authorities maintain a network of teletypewriter communication facilities for disseminating the weather data to other meteorological stations, while radio broadcasting is used for the benefit of airmen. Plans are in hand for extending to other parts of the United States this application of radio methods to aerological observations.

\section{Value of an Auxiliary Language}

A PAPER by M. Talmey on the auxiliary language question, in which the value of an auxiliary language as an agency for world peace is discussed, has been reprinted from the Modern Language Journal of December 1938. Dr. Talmey discusses the basic requirements of an auxiliary language, particularly the importance of being more expressive than the natural languages and strictly neutral. It must also be as suitable for the expression of all ideas as the most efficient natural languages are. He discusses the development of Esperanto in the United States and the reasons for its failure, and then describes the origin and development of a new international system known as 'Arulo' or 'Gloro', which aims at removing the ambiguity which characterizes most modern languages. In this system the main parts of speech are recognizable by characteristic endings, of which there are eighteen, six occurring very rarely. $\mathrm{He}$ suggests that the fitness of a language for translation is the best criterion of its efficiency.

\section{The School Health Services}

A BookLet entitled "The School Health Services: their Initiation, Growth and Character" has been issued by the National Union of Teachers, Hamilton House, Mabledon Place, London, W.C.1. It is a review by the Union designed to show how the school health services came into being, how they have developed, and what part the National Union has taken in theur initiation, conduct and progress. Provision of meals, medical and dental inspection and treatment, - physical education and school camps are some of the subjects dealt with, and finally recommendations are put forward which it is considered would improve the services. The memorandum is primarily intended for the information of members of the Union, but has been issued to the public in the hope that it may prove of use to those concerned with the health and fitness of the children of the nation.

\section{Oxford Science}

THE second quarterly issue of this publication maintains the high standard and interest of the first number. There are two articles on the teaching of chemistry at Oxford, one by an undergraduate, the other by Dr. J. H. Wolfenden, the former deliberately critical and even fault-finding, the latter an admirable exposition and defence of the unique system of training that has been in force at Oxford during the past seventeen years. The possibilities of science as an education are discussed by Dr. J. Z. Young. $\mathrm{He}$ advocates means of making scientific courses more valuable as a part of general education so that whoever takes them may in some sense be educated and not, as too often at present, merely filled with plain facts. There are two articles on popular lines. Dr. A. H. Cooke of the Clarendon Laboratory gives a short account of the technique used there in attaining low temperatures and discusses briefly the more important results that have been obtained; Prof. J. H. Burn discusses the phrase 'suffering from bloodpressure' in a paper which will be read with interest by all and with relief by some. In "Correspondence" the Nuffield professor of clinical medicine criticizes some of the suggestions about the medical curriculum made by one of the medical tutors in an article in the first issue. There are also reviews of scientific books and short accounts of the activities of the scientific and medical undergraduate societies.

\section{History of Cholera in Poland}

IN his inaugural thesis (Thèse de Paris, 1938, No. 739) Dr. Kac Hirsz, a native of Warsaw, gives an interesting account of the history of cholera in his country, in which there were six epidemics of the disease between 1831 and 1902, the last of which persisted until 1915. The study of cholera epidemics in Poland as in the rest of Europe shows that they start in the East and then follow as a rule one of two routes, namely, (1) by land, passing through Astrakan and Russia, or (2) by sea, when they are conveyed by pilgrims coming from Mecca who had landed at Odessa. Since the first epidemic in $\mathbf{1 8 3 1}$ all the countries in Western Europe have taken a lively interest in the behaviour of cholera in Poland and have actively collaborated with the Government of that country in a campaign against the disease.

\section{Progress in Photochemistry}

THE third report of the Committee on Photochemistry (Reprint and Circular Series of the National Research Council, No. 108, July 1938) contains eleven review articles dealing with various aspects of recent photochemical research written by seven different authors. Each is provided with a bibliography. There is a long table of quantum yields which gives a very useful review of this part of the subject. The report strikes a good balance between theory and experimental methods.

\section{Large Sunspots}

Two new large groups of sunspots have recently appeared. Particulars from the Royal Observatory, Greenwich, are as follows, the areas being measured on April 21 and expressed in millionths of the sun's visible hemisphere.

$\begin{array}{cccc} & \text { Central Meridian } & \\ \text { Date on Disk } & \text { Passage U.T. } & \text { Latitude } & \text { Area } \\ \text { April 20-May 2 } & \text { April 26.1 } & 27^{\circ} \mathrm{N} . & 1050 \\ \text { April 20-May 2 } & \text { April 26.6 } & 16^{\circ} \mathrm{S} . & \mathbf{1 3 5 0}\end{array}$

Chromospheric activity in the region of the first group was noted on April 21, an extensive bright eruption beginning at $9^{\mathrm{h}} 3^{\mathrm{m}}$ and lasting for about half an hour. 